\title{
Forty Years After Warnock: Special Needs Education and the Inclusion Process in Denmark. Conceptual and Practical Challenges
}

\author{
Niels Egelund ${ }^{1 *}$ and Camilla Brørup Dyssegaard ${ }^{2}$ \\ ${ }^{1}$ Department of Education, Aarhus University, Aarhus, Denmark, ${ }^{2}$ Independent Researcher, Holte, Denmark
}

The 1978 Warnock report enshrined the policy of inclusion and changed the way we talk about disability starting in the UK and following became a worldwide trend especially after the Salamanca Statement in 1994. The report thus had a groundbreaking effect on how children with special educational needs should be educated. This article is a tribute to the Warnock report and takes the reader to Denmark to see how special education, inclusion, and differentiated instruction in comprehensive schools have been on the agenda in Denmark. Several schools and municipalities have tried to use resources

OPEN ACCESS

Edited by:

Julie Elizabeth Dockrell,

UCL Institute of Education,

United Kingdom

Reviewed by:

Gregor Ross Maxwell,

UiT The Arctic University of Norway,

Norway

Gottfried Biewer

University of Vienna, Austria

*Correspondence:

Niels Egelund

egelund@edu.au.dk

Specialty section:

This article was submitted to

Special Educational Needs,

a section of the journal

Frontiers in Education

Received: 17 January 2019

Accepted: 23 May 2019

Published: 06 June 2019

Citation:

Egelund N and Dyssegaard CB (2019)

Forty Years After Warnock: Special

Needs Education and the Inclusion

Process in Denmark. Conceptual and

Practical Challenges.

Front. Educ. 4:54.

doi: 10.3389/feduc.2019.00054 on special education to promote inclusion and differentiation, but rules and regulations and clear incentives for exclusion have hindered this. Only after changing the concept of special education and the introduction of incentives for inclusion in Denmark, the trend has been radically changed. However, there are clear signs that teachers have not yet adapted to the idea of inclusion and are in need of specialist services and resources.

Keywords: differentiated instruction, incidence, inclusion, prevalence, school psychology, special education and special needs education

\section{INTRODUCTION}

The 1978 Warnock report led the way for the Education Act in 1981 in the UK. The report coined the concept of special educational needs. It substituted the concept of special education from the 1944 Education Act that had stipulated ten categories of individual "handicaps." The new concept moved the educational focus from the student's individual learning impairment or disability to the student's educational requirements. The report also built on an assumption that about two per cent of school-age children had severe learning disabilities or other difficulties that affected their education so much that a special school placement was necessary. The report thus had a groundbreaking effect on how children with special educational needs should be educated and in what settings.

In Denmark the Education Act from 1958 made the establishment of special education mandatory for municipalities. In 1993-a year before the 1994 Salamanca Declaration-a new Education Act was passed stating that instruction should be differentiated to suit the needs of all children in the comprehensive school, in order to minimize the need for special education. Moreover, in 2003, a change in the act encouraged the grouping of pupils within and across classes as a means of differentiation. The concept of inclusion was not adapted to the Danish language before 2005, when the ideas from the Salamanca Declaration led to the coining of a Danish word "rummelighed" meaning spaciousness even as the concept of special education and the medical model continued to rule. 
In 2003 the Ministry of Education decided to make a quantitative and qualitative investigation of the use of special education as a supplement to regular education in Danish regular classes.

The quantitative study covered a random sample of 290 Danish public schools. The study showed that the prevalence of special education was $8.8 \%$ (SD 3.97) with a total variation from 0 to $26 \%$. The qualitative study compared eight schools matched on demographic factors but with extreme levels (high or low) of prevalence. The study was reported in Danish (Egelund, 2003). In total there were surprisingly few relations between the prevalence of special education and factors often associated with the need for special education, such as resources for regular teaching, school size, municipality size, degree of urbanization, and geographical location.

A low prevalence of special education seemed to be related to other factors. First of all, the governing rules at that time encouraged a high prevalence of special education and the use of traditional special education as the only means of taking care of special needs. In fact, schools with low prevalence broke the rules omitting the requirement of a pedagogical and psychological evaluation of the student before using special education resources-with the consent of the local municipal authorities that owned the schools. The same schools also looked upon special needs as a natural product of human diversity and adapted the regular educational program to take these needs into account. This adaptability was closely related to the flexible organization of the school, also regarding the physical environment, where rooms for group work were available and where walls between classes could be removed, rendering teaching of both large and small groups possible. What was perhaps most important was the presence of teachers with teaching experience in special education and school psychologists as a key resource, providing collaborative consultancy, and supervision to teachers within the standard classroom setting. Finally, both pupils and parents had positive attitudes toward diversity and provisions for special needs within the regular educational program. If a specialized intervention was deemed necessary, it was looked upon as a welcomed effort, not as a stigmatizing, unavoidable solution (Egelund, 2003). Thus, the ideas from the Warnock report and the Salamanca Declaration had spread to the grass root level in some schools. Following the results, the Danish Minister of Education proposed that the term special education should be reserved for use in special schools and special classes. The intention, however, raised concerns that municipalities would gradually remove the $8-12 \%$ of the resources that had until now been set aside for special education in regular classes.

In 2007, Denmark went through a structural reform merging 275 municipalities into 98. An implication of the reform was that the ownership and responsibility for special schools were transferred from the counties to the municipalities resulting in an easier access to these schools for the individual municipalities. While the 2003 study showed a tendency in many schools to introduce more inclusive measures in their regular classes, some schools chose to establish special classes. This trend continued up to and after the structural reform in 2007, when new managements were set up and the degree of municipal supervision was low. From a level of $4.8 \%$ segregation to special schools and classes in 2005, the segregation rose to $5.4 \%$ in 2009 mainly due to an increase in use of special classes (Statistics Denmark, 2014). This prompted a study of the use of resources for special education (Deloitte, 2010) showing that in 2009 , around $30 \%$ of all resources for schools in Denmark was used on special education with an almost equal division between segregated special education and special education in regular classes.

The above mentioned results had a great impact on the Danish politicians resulting in a new act in 2012 called "The Inclusion Act," stating that exclusion should be reduced to $4.0 \%$ in 2015. Moreover, the term special education was reserved for interventions with a weekly duration of 12 lessons $(9 \mathrm{~h})$ or more. Interventions of $<12$ lessons were now to be called "supplementary education and other academic support" and became the responsibility of the head teacher. An assessment and a statement from the Pedagogical Psychological Counseling Center were no longer needed.

To follow the development of more inclusive practices in regular schools the Ministry of Education engaged in several efforts. One was to establish a Resource Center for inclusion and special education (Ministry of Education, 2013). Another was to conduct a research project monitoring the process in the municipalities over the years 2013,2014, and 2015. The results from this project are reported in this article.

\section{THEORY}

The guiding principle in special education in Denmark officially follows the 1994 Salamanca Statement: "The fundamental principle of the inclusive school is that all children should learn together, where ever possible, regardless of any difficulties or differences they may have. Inclusive schools must recognize and respond to the diverse needs of their students, accommodating both different styles and rates of learning and ensuring quality education to all through appropriate curricula, organizational arrangement, teaching strategies, resource use, and partnership with their communities. There should be a continuum of support and services to match the continuum of special needs encountered in every school" (Salamanca Declaration, 1994, p. 11-12).

A systematic review of international literature on inclusion performed for the Danish Ministry of Education in connection with The Inclusion Act showed that it is of vital importance for the academic and social development of students with special needs that the school has a stated objective to and positive attitudes toward inclusion. Teachers with negative attitudes toward inclusion of students with special needs, have negative effects on the development of all students (Dyssegaard et al., 2013). This follows Ainscow et al. (2006): “The development of inclusion, therefore, involves us in making explicit the values that underlie actions, practices and policies, and learning how to better relate our actions to inclusive values" (2006, p. 23). Furthermore, it follows Booth and Ainschow (2002) in their 
three dimensions of the Index for inclusion: (1) Production of inclusive policies. (2) Evolving inclusive practices. (3) Creating inclusive cultures.

The present research project looked at production of inclusive policies, evolving inclusive practices and the creation of inclusive cultures in Denmark from 2013 to 2015 . The objective for the study was to describe the 12 municipalities' transition process following the new rules set out in "The Inclusion Act" from 2012. The main focus of the research project was to describe how the municipalities both pedagogically and administratively handled the transition toward a higher inclusion rate.

\section{METHODS}

The design of the research project was a panel study that was conducted three times in the years 2013, 2014, and 2015 in 12 municipalities representing demographic differences in Denmark. The research project was conducted according to principles in the "The Danish Code of Conduct for Research Integrity" which provides the research community with a framework to promote commonly agreed principles and standards. The Code of Conduct aims to support a common understanding and common culture of research integrity in Denmark (Ministry of Higher Education and Science, 2014). The design and approach to the research project was furthermore approved by the Danish Ministry of Education. Further approval by an Ethics Committee was not required as per applicable institutional and national guidelines and regulations. The 12 municipalities were invited to participate in the project. The 12 municipalities are completely anonymous. The completion of questionnaires was completely voluntary and also anonymous. In this way the informed consent of the participants was implied through survey completion. Participants in the interviews were invited by mail stating the purpose of the project and they were asked to give their consent in a reply mail. All participants were above the age of 23 .

From the 12 municipalities a multitude of information was collected: municipal documents about inclusion and special education were collected and studied; demographic information about municipalities and schools were found, data about economic resource allocations and student mobility were collected from the municipal administrations; qualitative interviews were conducted with school directors and leaders of the Pedagogical Psychological Counseling Center about strategies and procedures; questionnaires about strategies and procedures for inclusion were completed by school principals $(N=146)$; questionnaires were completed by teachers in the 2nd and 8 th grades about their work with inclusion $(N=448)$. Due to great discrepancies between the principals' and teachers' answers over the 3 year period it was decided to supplement the data with focus group interviews. Focus group interviews were carried out in 19 schools, two schools in seven of the twelve municipalities and one school in the remaining five municipalities. Participants in the interviews were the school principals, union representatives, heads of school resource centers, and teachers.
TABLE 1 | Description of the 12 municipalities in the study.

\begin{tabular}{lllccc}
\hline $\begin{array}{l}\text { Municipality } \\
\text { ID }\end{array}$ & Size* $^{*}$ & $\begin{array}{c}\text { Urban/ } \\
\text { rural }\end{array}$ & $\begin{array}{c}\text { Inclusion } \\
\mathbf{2 0 1 0}\end{array}$ & $\begin{array}{c}\text { Social and } \\
\text { economic index** }\end{array}$ & $\begin{array}{c}\text { Diff. from } \\
\text { expected }\end{array}$ \\
\hline A & Small & Urban & $94.2 \%$ & 0.47 & -1.8 \\
B & Medium Urban & $96.1 \%$ & 0.71 & 0.0 \\
C & Medium & Urban & $89.7 \%$ & 1.64 & -2.3 \\
D & Medium Rural & $92.5 \%$ & 0.88 & -1.9 \\
E & Medium Rural & $92.0 \%$ & 1.13 & -2.0 \\
F & Small & Rural & $97.5 \%$ & 0.86 & +2.0 \\
G & Big & Urban & $94.9 \%$ & 1.15 & +1.4 \\
H & Medium & Rural & $92.3 \%$ & 1.06 & -1.8 \\
I & Medium & Rural & $91.8 \%$ & 0.86 & +0.1 \\
$\mathrm{~J}$ & Small & Rural & $91.7 \%$ & 1.00 & -0.4 \\
$\mathrm{~K}$ & Medium & Rural & $89.5 \%$ & 1.09 & -2.5 \\
L & Medium Rural & $94.9 \%$ & 1.09 & +1.2 \\
\hline
\end{tabular}

"Size: Small < 30,000 inhabitants. Medium 30,000-70,000 inhabitants. Big > 70,000 inhabitants.

${ }^{* *}$ Based on percentage of the population in age 20-59 years in workforce, number of psychiatric patients, percentage of single parents, percentage of population on public support. 1.0 is average for Denmark. High values are indicators of low social economy and vice versa.

The qualitative analysis of data used a thematic structure as the basis for organizing and reporting the study findings from semi-structured interviews and from documents and materials collected in municipalities and schools. Quantitative data from questionnaires were analyzed using STATA and $t$-test or Wilcoxon-Mann-Whitney $U$-test.

Four reports have been published in Danish (Baviskar et al., 2013, 2014, 2015; Dyssegaard and Egelund, 2015).

\section{RESULTS}

The research project covers a broad range of municipality sizes, urban/rural regions and social and economic status found in Denmark. Table 1 gives a view of the differences in the first three columns. There is an interesting wide range in inclusion percentage in 2010 and a difference in expected inclusion percentage based on student social background. These results are presented in the fourth to sixth columns in the table.

\section{Inclusion Rates From 2010 to 2015}

The twelve municipalities differed in their inclusion percentage in 2010 between 89.5 and $96.1 \%$. Inspections of columns four and five in Table $\mathbf{1}$ show that there is a relation between degree of segregation and average educational and economical level of the municipality. But further calculations shown in column seven reveal differences from the expected level. The differences amount to between plus 2.0 percentage points to minus 2.5 percentage points.

Table 2 presents the development in inclusion from 2010 to 2015. Two phases are identified; one covers the time from 2010 until the implementation of The Inclusion Act in 2013, the other covers the 3 years after implementation (from 2013 to 2015).

In 2013 there was a variation in inclusion percentage from 91.3 to 98.3 with an average of $94.1 \%$. The change from 2010 is 
TABLE 2 | Change in inclusion percentage from 2010 to 2015 in the 12 municipalities.

\begin{tabular}{|c|c|c|c|c|c|c|c|}
\hline Municipality ID & $\begin{array}{c}\text { Inclusion } \\
\text { percentage } 2010\end{array}$ & $\begin{array}{c}\text { Inclusion } \\
\text { percentage } 2013\end{array}$ & $\begin{array}{c}\text { Inclusion } \\
\text { percentage } 2014\end{array}$ & $\begin{array}{c}\text { Inclusion } \\
\text { percentage } 2015\end{array}$ & $\begin{array}{c}\text { Change } \\
2010-2013\end{array}$ & $\begin{array}{l}\text { Total change } \\
\text { 2013-2015 }\end{array}$ & $\begin{array}{c}\text { Total change } \\
\text { 2010-2015 }\end{array}$ \\
\hline$A$ & $94.2 \%$ & $94.4 \%$ & $95.1 \%$ & $95.7 \%$ & -0.2 & +1.3 & +1.1 \\
\hline$B$ & $96.1 \%$ & $97.0 \%$ & $97.4 \%$ & $98.0 \%$ & +0.5 & +1.0 & +1.5 \\
\hline C & $89.7 \%$ & $91.4 \%$ & $92.3 \%$ & $92.5 \%$ & +1.0 & +1.1 & +2.6 \\
\hline D & $92.5 \%$ & $93.2 \%$ & $94.1 \%$ & $95.2 \%$ & +0.2 & +2.0 & +2.2 \\
\hline$E$ & $92.0 \%$ & $94.3 \%$ & $95.6 \%$ & $96.5 \%$ & +0.9 & +2.2 & +3.1 \\
\hline$F$ & $97.5 \%$ & $97.8 \%$ & $97.6 \%$ & $97.5 \%$ & +0.2 & -0.3 & $-0,1$ \\
\hline G & $94.9 \%$ & $95.9 \%$ & $96.4 \%$ & $96.8 \%$ & +0.2 & +0.9 & +1.1 \\
\hline $\mathrm{H}$ & $92.3 \%$ & $94.3 \%$ & $94.3 \%$ & $94.5 \%$ & +1.2 & +0.2 & +1.4 \\
\hline I & $91.8 \%$ & $96.3 \%$ & $96.0 \%$ & $96.8 \%$ & +2.6 & +0.5 & +3.1 \\
\hline J & $91.7 \%$ & $94.5 \%$ & $95.4 \%$ & $95.2 \%$ & +0.8 & +0.7 & +1.5 \\
\hline K & $89.5 \%$ & $91.3 \%$ & $92.2 \%$ & $93.7 \%$ & -0.2 & +2.4 & +2.2 \\
\hline L & $94.9 \%$ & $98.3 \%$ & $99.2 \%$ & $98.2 \%$ & +2.7 & -0.1 & +2.6 \\
\hline Average & $93.1 \%$ & $94.9 \%$ & $95.5 \%$ & $96.0 \%$ & +0.8 & +1.0 & +1.9 \\
\hline
\end{tabular}

due to the fact that some of the municipalities started inclusion processes early.

\section{Changes From 2010 to 2013}

Four of the municipalities, E, H, I, and L had an increase in inclusion from 2010 to 2013 of 0.9 to impressive 2.6 and 2.7 percentage points. Documents and interview data from the municipalities revealed which strategies and practices led to the increase in inclusion. Municipalities I and L had almost identical strategies. They started by closing a number of small schools and at the same time implemented inclusion measures. Municipality I established a municipal resource team, changed focus from an individual perspective to a systemic perspective, trained teaching consultants and introduced cooperative learning. Municipality L closed all its special classes and included the special school in a regular school at the same time halving the capacity. All teachers were upgraded in inclusive practices by changing focus from an individual perspective to a systemic perspective. An important aspect was that all resources followed the included students and an extra resource of $\sim 1$ million EUR was added to the schools for inclusion. Municipality E closed eight small schools and the rest were merged to four district schools. One fourth of all special class students were transferred to regular classes with their resources. All teachers received an upgrade in inclusion and teacher consultants were trained by the local university college. Municipality $\mathrm{H}$ differed from the three others by working on inclusion from 2010 and established a distinct vision and a strategy for inclusion using dialogue groups representing headmasters, teachers and parents in 2012.

Two municipalities, $\mathrm{A}$, and $\mathrm{K}$ did not commence on any distinct initiatives to increase inclusion up to 2013. A had established and overall strategy in 2011, and the individual schools had made their own strategies, but nothing had been done to reduce special settings or to introduce economic incentives. $\mathrm{K}$ had a plan for analyzing the situation in the specialized area in 2010, but no actual initiatives were taken before 2013 when a new school director and new head of Pedagogical Psychological Counseling Service were appointed.
Municipality $\mathrm{F}$ differed from all the other municipalities in having a significant focus on inclusion from 2003. There was no real need to increase inclusion which was already relatively high (97.6\%).

Municipality $\mathrm{C}$ has had the lowest rate of inclusion and also had the lowest socio-economical background in Denmark, but still the rate was lower than expected. An overall definition of inclusion was agreed upon in 2011, where the overall aim was to reduce segregation with $5 \%$ pr. year over a 3 year period. The municipality was not interested in establishing economic incentives. In 2013 there was a reduction of 1 percentage point since 2010.

The last four municipalities, B, D, G, J all had established principles, strategies, goals, and projects aiming at reducing segregation and succeeded in increasing inclusion up to 2013 from 0.2 to 0.8 percent points.

\section{Changes From 2013 to 2015}

After 2015 there was an increase in inclusion of from 0.2 to 2.4 with an average of 1.0. The municipality with 2.4 is $\mathrm{K}$, which was the last to start and chose to close all special classes and half of their special schools in 2014. The special classes had been converted to inclusion centers at three schools with a close collaboration with regular classes. A municipal goal of the maximum number of students in the special schools had been established for 2016. For all twelve municipalities the average in 2015 became $96.0 \%$.

After collection of documents, data collection in municipal administrations, visits in the municipalities to interview school directors and heads of the Pedagogical Psychological Counseling Centers, analysis of the data showed that in 2013, ten of the twelve municipalities had started the process of inclusion by setting up goals, by establishing strategies, by providing in-service training to all teachers and specialist training of teachers as inclusion consultants. In 2014, all twelve municipalities had commenced working on promoting inclusion processes. In 2013, nine of the municipalities had introduced a system with economic incentives for inclusion; in 2014 yet another municipality had taken up the 
TABLE 3 | Supplementary education.

\begin{tabular}{lccc}
\hline Organization form & $\mathbf{2 0 1 3}$ & $\mathbf{2 0 1 4}$ & $\mathbf{2 0 1 5}$ \\
\hline Co-teaching & $41.5 \%$ & $45.4 \%$ & $33.8 \%$ \\
Resource center outside of regular classroom & $32.1 \%$ & $19.7 \%$ & $29.4 \%$ \\
Teacher assistant & $8.4 \%$ & $11.0 \%$ & $12.1 \%$ \\
Other forms & $18.0 \%$ & $23.9 \%$ & $29.6 \%$ \\
\hline Total & $100.0 \%$ & $100.0 \%$ & $99.9 \%$ \\
\hline
\end{tabular}

"How is supplementary education organized in the school" (according to school headmasters) $N=146$.

principle. In 2015 another municipality had started to consider adapting the principle.

\section{Incentives for Inclusion}

The system of the incentives for inclusion was that schools were financed by a fee for each student in their school district. The fee was adjusted according to grade level and in most cases for parents' average social and economic status in the school district. The fee was based on the municipal expenditure for regular education and special education in 2011-2012 (before The Inclusion Act and system change) and was adjusted each year to adjust for inflation. Fees were paid up front for each school year. If a school wanted to send a student to a special class or a special school, the school had to pay for the service. In most cases it was a fixed amount around 10,000 EUR per year, in some cases the actual amount could go up to 60,000 EUR per year. If a school brought a segregated student back to the local school, the school was paid either the fixed amount or the full price for that student.

\section{Reduction of Special Education}

The new Danish system worked. For the first time since the Salamanca Statement the percentage of segregated students was reduced. The average inclusion percent for the twelve municipalities had gone from 94.1 in 2010 to 94.9 in 2013 and 96.0 in 2015. The establishment of a municipal strategy deliberately closing special classes and thus preventing the possibility of segregation was very efficient and had been used in four municipalities. The establishment of incentives for inclusion worked at the school level, where headmasters generally avoided placement in segregated settings.

\section{Supplementary Education}

The new act has made it possible for school headmasters and their teachers to establish early and dynamic solutions tailored to individual students without having to wait for an assessment from the Pedagogical Psychological Counseling Center. In 2011, the prevalence for special education as a supplement to regular classes was $6.66 \%$; in 2015 it was down to $0.025 \%$ (Ministry of Education, 2015). The prevalence of supplementary education was $5.5 \%$ in 2013 and $5.6 \%$ in 2014 but with a huge variation between schools. Out of 146 schools seven have no students who receive supplementary education.

As shown in Table 3, supplementary education was, in 2013 , given as co-teaching for $42 \%$ of all students, for $32 \%$
TABLE 4 | Headmaster's and teacher's answer to the question: "How do you agree or disagree with the goal of decreasing the proportion of students receiving special education and thereby increasing the proportion of students in regular education from 94.4 to $96.0 \%$ ?."

\begin{tabular}{|c|c|c|c|c|c|c|}
\hline \multirow{2}{*}{$\begin{array}{l}\text { Respondents } \\
\text { Year }\end{array}$} & \multicolumn{3}{|c|}{ Headmasters } & \multicolumn{3}{|c|}{ Teachers } \\
\hline & 2013 & 2014 & 2015 & 2013 & 2014 & 2015 \\
\hline $\begin{array}{l}\text { Agree to a high } \\
\text { degree }\end{array}$ & $29.3 \%$ & $36.2 \%$ & $32.3 \%$ & $3.5 \%$ & $3.3 \%$ & $3.6 \%$ \\
\hline Agree & $50.0 \%$ & $38.3 \%$ & $33.9 \%$ & $15.2 \%$ & $9.6 \%$ & $11.7 \%$ \\
\hline $\begin{array}{l}\text { Neither agree or } \\
\text { disagree }\end{array}$ & $15.5 \%$ & $14.9 \%$ & $24.2 \%$ & $17.8 \%$ & $15.5 \%$ & $17.4 \%$ \\
\hline Disagree & $5.2 \%$ & $6.4 \%$ & $9.7 \%$ & $27.8 \%$ & $30.1 \%$ & $27.7 \%$ \\
\hline $\begin{array}{l}\text { Disagree to a high } \\
\text { degree }\end{array}$ & $0.0 \%$ & $2.1 \%$ & $0.0 \%$ & $33.5 \%$ & $38.2 \%$ & $36.9 \%$ \\
\hline Do not know & $0.0 \%$ & $2.1 \%$ & $0.0 \%$ & $2.2 \%$ & $3.3 \%$ & $2.8 \%$ \\
\hline Total & $100.0 \%$ & $100.0 \%$ & $100.1 \%$ & $100.0 \%$ & $100.2 \%$ & $100.1 \%$ \\
\hline
\end{tabular}

TABLE 5 | Headmaster's and teacher's answer to the question: "Have you in your school had 1 day of in-service training on inclusion?"

\begin{tabular}{llllllll}
\hline \multirow{2}{*}{ Respondents } & \multicolumn{3}{c}{ Headmasters } & & \multicolumn{3}{c}{ Teachers } \\
\cline { 2 - 4 } \cline { 7 - 8 } Year & $\mathbf{2 0 1 3}$ & $\mathbf{2 0 1 4}$ & $\mathbf{2 0 1 5}$ & & $\mathbf{2 0 1 3}$ & $\mathbf{2 0 1 4}$ & $\mathbf{2 0 1 5}$ \\
\hline Yes & $72.4 \%$ & $61.2 \%$ & $25.3 \%$ & & $33.6 \%$ & $31.7 \%$ & $14.5 \%$ \\
No & $27.6 \%$ & $38.8 \%$ & $74.7 \%$ & $66.4 \%$ & $68.3 \%$ & $85.5 \%$ \\
\hline Total & $100.0 \%$ & $100.0 \%$ & $100.0 \%$ & $100.0 \%$ & $100.0 \%$ & $100.0 \%$
\end{tabular}

as referral to the resource center, for $8 \%$ as teacher assistant and for $18 \%$ by other measures. In 2014, the percentages were $45 \%$ co-teaching, $20 \%$ referral to resource center, $11 \%$ teacher assistant and $20 \%$ as other measures. In 2015, the percentages were $34 \%$ co-teaching, 19\% referral to resource center, $12 \%$ teacher assistant, and $25 \%$ as other measures. Other measures primarily covered the formation of small groups within the classes and support and supervision from special educators, inclusion consultants and the Pedagogical Psychological Counseling Centers.

\section{Success in Creation of an Inclusive Culture?}

Data from the school headmasters and teachers, however, showed that teachers especially were reporting a low degree of acceptance of the principles of inclusion (Table 4).

Over the years from 2013 to 2015 between 75 and $79 \%$ of the headmasters agreed to the principle of inclusion while the same was only the case for between 14 and $19 \%$ of the teachers. In the same period of time only 5 to $10 \%$ of the headmasters disagreed while between 62 and $68 \%$ of the teachers disagreed.

In Denmark the most common form of in-service training is to devote a full day-usually a Saturday-to a common theme. The headmasters and teachers were asked about how often this had happened over the years from 2013 to 2015. The results are shown in Table 5. 
When it came to competence building, $72 \%$ of all school headmasters in 2013 said, they had arranged a thematic day about inclusion. For 2014 the percentage was 61 and for 2015 it was 25. The fact that the percentage decreased over the years can be seen as a natural result from a need which is fulfilled. It is, however, remarkable that the teachers only reported that over the 3 years, respectively, 34,32 , and $15 \%$ had participated in a thematic day about inclusion.

The huge differences in attitudes toward inclusion and participation in in-service training in inclusion indicate problems regarding establishing an inclusive culture at school level. The survey data could not account for these huge discrepancies. Therefore, extended qualitative interviews on obstacles to inclusion were set up with all 12 school directors and heads of Pedagogical Psychological Counseling Centers: Moreover, focus group interviews in 19 schools were arranged and concluded just before the end of the project in June 2015.

\section{Obstacles to Inclusion}

Qualitative analysis of interview data from the 12 school directors and 12 heads of Pedagogical Psychological Counseling Centers in the spring of 2015 covered six areas: acceptance of the strategic goals, competency development, feeling of self-efficacy, use of counseling, too many changes in a short span of time and lack of available resources.

The data about acceptance of strategic goals, originating from the Parliament and adapted by the municipalities, showed two common themes. One was that it is a top-down decision, where headmasters had to be loyal to the decisions in the local governments and its school administration, while teachers did not have a clear understanding of what the intention and the objective for inclusion was. The other was the frustrations teachers felt in their daily work having to deal with students with special needs and at the same time having to teach two more hours pr. week even as they had less time for preparation as a result of the settlement for duty hours after a teacher lock out in the spring of 2013.

When it comes to competency development there were again two common themes. One was that the teachers experienced the content and quality as insufficient. They found that the inservice training provided had been very theoretical and change of attitude oriented and that some of the instructors had talked down to the teachers making them feel insufficient. The other was that the teachers wanted to have University College courses related to different types of diagnosis while learning in the classroom. They believed this might have been more effective, but it was seldom an option.

Regarding teacher's feeling of self-efficacy there were three common themes: powerlessness, the challenges of teamcooperation and the desire to have two teachers in the classroom. Powerlessness covers that teachers in their daily work in the classrooms wanted a "tool box" where they could grab a course of action when for instance a student with ADHD showed aggressive behavior or when a student with autism withdrew. They felt that they were unable to handle differentiation of instruction and manage the classroom. Team-cooperationwhich had been gradually introduced in Danish schools from the mid 1990'es to raise professional performance of teams-covers that teachers found it difficult to engage in an actual cooperation with their colleagues in their teams concerning classes or subjects because of lack of time. Finally wanting two teachers in the classroom was related to feelings of being insufficient in regard to handling the teaching situation, and also to extra help as a good general solution for all types of problems.

Use of counseling services had two common themes. The first and most prominent was the existence of cultural gulfs. In the history of the teaching profession one class, one teacher, one classroom had been the dominant setting, and introducing an inclusion consultant in the classes had been difficult for many teachers, especially if the expert had less total teaching experience and subject knowledge plus perhaps was younger than the subject teacher. Some teachers avoided consultation and supervision and therefore did not report their problems to the headmaster or to the head of the resource team. The other theme was that some of the appointed consultants, who often had extensive experience in special classes and special schools, had difficulties in working in classrooms with up to 28 students and giving advice to subject teachers.

Too many changes in a short span of time was a common theme which covered that the time period from 2012 to 2014 had seen three major reforms of the primary and lower secondary school in Denmark. The Inclusion Act required school headmasters to deal with decisions about allocation of human resources for supplementary education and financial resources to special education in segregated settings, in most cases with economic incentives. The settlement for duty hours after a teacher lockout came, as noted earlier, in the spring of 2013. A comprehensive school reform introducing a longer school day $(30 \mathrm{~h}$ a week for the youngest students and $35 \mathrm{~h}$ a week for the oldest students), subject supporting activities, more physical activities and homework hours was enacted in 2014. Finally, the school administration in five of the twelve municipalities had undergone profound changes with new structures, new management, and new procedures.

Lack of available resources covered one common theme: reduction in budgets. First of all, the economic incentives implies that resources for special needs were paid up front and were expected to be allocated to each student with special needs. This was true in ten of the twelve municipalities, but in five municipalities it was clearly felt as "giving with one hand and taking with the other" as there had been general cutbacks in funding in the aftermath of the global economic crisis in 2008. Moreover, there had been an average reduction of number of students of $2.04 \%$ covering a span from +4.18 to $-7.53 \%$ causing the school budgets to shrink accordingly while expenses to buildings and administration were at the same level.

\section{Final Focus Group Interviews}

As mentioned previously the rationale behind the focus group interviews was to study in depth the differences in attitudes and opinions shown in the quantitative data from school headmasters and teachers. Participants in the focus group interviews were the school headmaster, the teachers' union local representative, the head of the school resource centers and one or two teachers. 
There were seven areas to be covered in the interview: use of resources for students with special needs, competency development, use of counseling services, use of teamcooperation, ensuring students' academic progression, the most effective inclusion practices.

On the subject of use of resources for students with special needs the dominant theme in eight of the 19 schools was that there were too few resources, and this was to a high degree caused by general reductions in funding of the schools. Different funding practices also created problems. The most common practice was to set up a plan where resources were allocated for students/classes for each half school year, but then, when new needs arose, they had to wait for up to 5 months. Another common practice, especially in the bigger schools, was to allocate the resources to the teams around the classes, but this reduced flexibility. For instance, it was difficult to move resources from one grade level to another if new needs arose. Only very seldom there was an unused reserve capacity in the budget, and therefore teachers trained as inclusion counselors often were used as "fire fighters," reducing their time for counseling. In two schools special teachers or assistants were used as substitutes when other teachers were sick.

Regarding competency development the focus group interviews confirmed that there was a gap between the content in general in-service training given and the perceived needs of the teachers. This was a complaint mentioned by a majority of the school union representatives. Almost all schools had used a major part of their resources for competency development to train one of their special education teachers as inclusion counselors, but the same training had made the new inclusion counselors very attractive for other schools, and about one fifth of the counselors had moved to another school or even another municipality and then there were not enough resources left at the schools to immediately train a new inclusion counselor.

All 19 schools have or have had teachers trained as inclusion counselors. As mentioned above some have left for other appointments creating vacancies. In about half of the schools there are complaints that inclusion counselors are used as "fire fighters" when teachers or students have issues leaving little time for planned and structured class room observation and supervision of teachers.

Eleven schools had introduced structured team discussions of their students learning progression. For students with special needs, barriers to learning were discussed, intervention strategies were planned and introduced, and after 3 to 4 weeks results were evaluated followed by adjustment of the intervention strategy if needed. This response to intervention strategy seemed highly efficient. In five schools the inclusion counselor or teachers from the resource center participated in team meetings on a regular basis to give advice on how to deal with students with special needs. Only one school said that they lacked systematic discussions of teaching students with special needs in their teamcollaboration.

Assuring students' academic progression was primarily done using informal teacher evaluations. Use of the national tests, which were introduced in 2010, had been met with resistance from many teachers because they felt it was a control instrument and not as a tool to inform their professional practice. Ten schools used the national tests to monitor the progression of students with special needs. The tests were given twice a year even though they are only required once a year. The national tests were in most cases supplemented by optional tests developed and sold by Danish publishing houses used by nearly all schools in Denmark. Nine schools only used the optional tests. The test results were discussed in the class teams and occasionally the school reading and mathematics expert teachers were consulted so that a thorough evaluation of student progress and advice on intervention tactics could be obtained. One school complains that the use of tests and other documentation takes too much time from preparation and the informal evaluation of lessons.

Effective inclusion practices were felt to be promoted mainly by the economic incentives where best use of resources was in constant focus, and often creative ways to avoid exclusion were found. However, in some cases less than optimal solutions were used due to economic constraints, and discontinuation in securing a certain number of extra hours per student led to teachers' feeling a shortage of resources. This pointed toward a need for ensuring a certain pool of hours for assistance to special needs students, including a reserve for acute interventions. Inservice training was effective if it fulfilled teachers' need of tools to use in their daily work with special needs students, and inclusion counselors needed to have competences and time enough in their schedule for their consultative work and subject teachers needed to accept guidance from colleagues. Finally, segregated settings for limited periods should not be seen to be in conflict with the inclusion strategy, it was sometimes a precondition for maximal inclusion in unison with a regular class.

In total the focus group interviews revealed that headmasters' and teachers' attitudes toward inclusion were less different than they appeared in the quantitative study. It seemed that headmasters' roles as civil servants and teachers' negative attitudes to the new settlement for duty hours had amplified their anonymous responses to the questionnaire. The headmasters felt the obstacles to inclusion in their daily work and tried to deal with them in the best way possible, and the teachers did their best to be professional under strict economic circumstances.

\section{DISCUSSION AND CONCLUSION}

The 1978 Warnock report changed the focus from the student's impairment or disability to the student's educational requirement and built on the assumption that only about two percent of all students needed a special school placement. The report also coined the concept of special educational needs substituting the old concept of special education, and this trend has now been adapted almost worldwide.

In Denmark special education became mandatory in 1958, and special education usually received funding from central resource bases in municipalities or counties. Although Denmark politically had adopted the principle of inclusion in the Salamanca Statement, the concept of special education needs was never adapted in the Danish language and educational practice. Exclusion to totally segregated settings started to grow in the 
mid 1990 'es driven by the tradition "let the specialists take care of the student's problems," the lack of incentives for inclusion and lack of oversight following a structural reform. The medical model of disabilities was still dominant in spite of some grass root movements from 1993 to 1994 at the local level.

In 2011 a total of around $30 \%$ of all economic resources for primary and lower secondary school in Denmark was spent on special education. This prompted a change. An Act of Inclusion was adopted in 2012 with the aim of bringing exclusion down to $4.0 \%$ in 2015 . The term special education was reserved for interventions with a weekly duration of 12 lessons $(9 \mathrm{~h})$ or more while interventions of less than 12 lessons were called "supplementary education and other academic support" and became the responsibility of the head teacher. The Danish Ministry of Education initiated a research project monitoring the process in 12 municipalities over the years 2013, 2014, and 2015. The results of this project are reported in this article.

In 2015 exclusion was down to $4.0 \%$ in the 12 municipalities. The prevalence of special education in ordinary schools was $0.15 \%$ while $5.6 \%$ were receiving supplementary education, most often from a co-teacher in the regular classroom. The 12 municipalities had had success replicating the ideas in the 1978 Warnock Report adapting the conceptual change from The Act of Inclusion and some changes in practice, but they still faced some practical challenges.

The quantative and qualitative results reported in this paper show that the basic drivers behind the change, except for the act, were municipal decisions to close special classes and special schools and the introduction of economic incentives for inclusion motivating headmasters to find other means than putting pupils with special needs into special classes and special schools. Seen from a theoretical perspective (Booth and Ainschow, 2002, Ainscow et al., 2006) there are three basic conditions to be met to promote inclusion: Production of inclusive policies, evolving inclusive practices and the creation of inclusive cultures.

The research project shows that inclusive policies had been established both at the parliament level and in the local governments. However, when it came to inclusive practices not all municipalities had been willing to create economic incentives

\section{REFERENCES}

Ainscow, M., Booth, T., and Dyson, A. (2006). Improving Schools, Developing Inclusion. London: Routledge.

Association of municipalities (2018). Børns Diagnoser og Skoletyper. (Childrens diagnosis' and school placement). Copenhagen Association of municipalities.

Baviskar, S., Dyssegaard, C. B., Egelund, N., Lausten, M., and de Montgomerey, C. (2015). Dokumentationsprojektet: Kommunernes Omstilling til øget Inklusion pr. Marts 2015, (The Documentation Project: Municipal change toward more inclusion per March 2015; in Danish). Department of Education, Aarhus University.

Baviskar, S., Dyssegaard, C. B., Egelund, N., Lausten, M., and Lynggaard, M. (2014). Dokumentationsprojektet: Kommunernes Omstilling Til øget Inklusion pr. Marts 2014, (The Documentation Project: Municipal change toward more inclusion per March 2014; in Danish). Department of Education, Aarhus University.

Baviskar, S., Dyssegaard, C. B., Egelund, N., Lausten, M., Lynggaard, M., and Tetler, S. (2013). Dokumentationsprojektet: Kommunernes Omstilling Til øget for inclusion and in many cases in-service training had focused too much on ideology and too little on daily practice in the classroom. Many teachers had not yet adapted to the values and ideas of inclusion, and they felt that they were pressured by topdown decisions, and there had in several municipalities been a general reduction in funding to schools and other public service institutions in the aftermath of the economic crisis of 2008. Specialist services and resources had been provided as inclusive practices, but often they were used for acute needs and in some cases, teachers had difficulties in accepting guidance from colleagues. Thus, both the establishment of inclusive practices and the creation of inclusive cultures were lagging behind the policy intentions. However, even with these limitations the goal of $96 \%$ inclusion was met in the 12 municipalities. They had finally come closer to the intention in the Warnock report.

Since $2015 \mathrm{a}$ few prominent changes have occurred in relation to inclusion. First of all, the official statistics have shown that for Denmark as a whole the exclusion rate has risen from 4.07 in 2015 to $4.39 \%$ in 2018 (Ministry of Education, 2018). Moreover, there has been a continuing rise in children and youth receiving a psychiatric diagnosis from 2009 to 2017 from 0.49 in 2009 to $0.79 \%$ in 2017 (Association of municipalities, 2018). The goal of including 96\% of all children in regular schools has also been removed from The Inclusion Act in 2016 by the government. These three changes could mean that the Danish school system may again be moving further away from the ideals in the Warnock report.

\section{AUTHOR CONTRIBUTIONS}

All authors listed have made a substantial, direct and intellectual contribution to the work, and approved it for publication.

\section{FUNDING}

The study is funded by The Danish Ministry of Education (Grant number 018.11N.391).
Inklusion pr. Marts 2013, (The Documentation Project: Municipal change toward more inclusion per March 2013; in Danish). Department of Education, Aarhus University.

Booth, T., and Ainschow, M. (2002). Index for Inclusion - Developing Learning and Participation in Schools. Bristol: CSIE.

Deloitte (2010). Analyse af Specialundervisning i Folkeskolen. (Analysis of Special Education in Public Primary and Lower Secondary Schools; in Danish). Copenhagen. Deloitte Business Consulting.

Dyssegaard, C. B., and Egelund, N. (2015). Dokumentationsprojektet. 19 skolers erfaringer med inklusion 2013 - 2015. En kvalitativ analyse, (The Documentation Project: Experiences with inclusion on 19 schools 2013-2015. A qualitative analysis; in Danish). Department of Education, Aarhus University.

Dyssegaard, C. B., Larsen, M. S., and Tiftikci, N. (2013). Effekt og Pcedagogisk Indsats Ved Inklu-sion af Børn Med Serlige Behov i Grundskolen: Systematisk Review. Effect and pedagocical intervention for students with special needs in primary and lower secondary school. A systematic review. Danish Clearinghouse for Educational Research, Department of Education, 
Aarhus University IUP, Aarhus University, Clearinghouse Research Serie; No. 13.

Egelund, N. (2003). Undersøgelse af Specialundervisningen i Dannmark, Danish. Copenhagen. (Study of Special Education in Denmark; in Danish). Pedagogical University Press.

Ministry of Education (2013). Strategi for Ressourcecenter for Inklusion og Specialundervisning, (Strategy for a Resource Centre for Inclusion and Special Education; in Danish). Copenhagen: Ministry of Education.

Ministry of Education (2015). Specialundervisning og Inklusion, 2014/15. (Special education and inclusion, 2014/2015) Copenhagen: Ministry of Education.

Ministry of Education (2018). Andelen af Elever I Den Almindelige Undervisning I 2017/2018. (Proportion of students in regular education in 2017/2018). Copenhagen: Ministry of Education.

Ministry of Higher Education and Science. (2014). The Danish Code of Conduct for Research Integrity, Copenhagen: Ministry of Higher Education and Science.

Salamanca Declaration (1994). Salamanca Erkloringen og Handlingsprogrammet for Specialundervisning, 7.-10. juni 1994, (Salamanca Declaration andAction
Programme for Special Education, June 7-10, 1994; in Danish) edition, 1997, Copenhagen: Ministry of Education; Unesco.

Statistics Denmark (2014). Specialundervisning i Grundskolen 2013/2014. (Special Education in Primary and Lower Secondary Education 2013/2014; in Danish). Copenhagen. Nyt fra Danmarks Statistik. 26. juni 2014. Nr. 340.

Conflict of Interest Statement: The authors declare that the research was conducted in the absence of any commercial or financial relationships that could be construed as a potential conflict of interest.

Copyright (C) 2019 Egelund and Dyssegaard. This is an open-access article distributed under the terms of the Creative Commons Attribution License (CC BY). The use, distribution or reproduction in other forums is permitted, provided the original author(s) and the copyright owner(s) are credited and that the original publication in this journal is cited, in accordance with accepted academic practice. No use, distribution or reproduction is permitted which does not comply with these terms. 